\title{
ANALISIS VIDEO MUSIK VIRTUAL AKUN KOMUNITAS @INDOMUSIKGRAM DI MEDIA SOSIAL INSTAGRAM
}

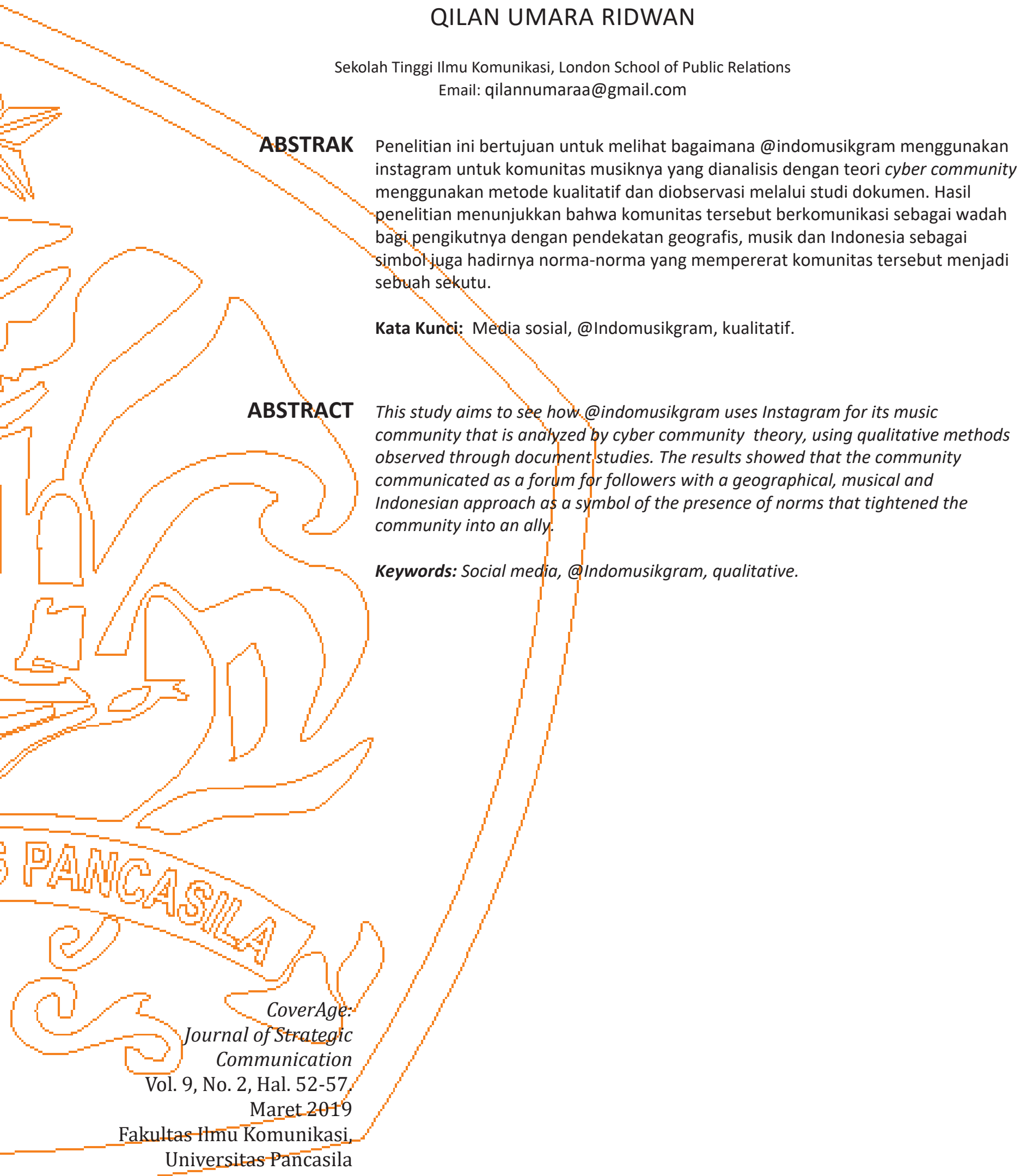

Diterima 7 Oktober 2018

Disetujui 14 Februari 2019 


\section{PENDAHULUAN}

Media sosial adalah wadah untuk bersosialisasi satu sama lain. Aktifitas media sosial dilakukan secara online di internet yang tidak dibatasi ruang dan waktu. Manfaat dari sosial media diantaranya, sebagai media untuk penjualan, promosi,memperluas pertemanan dan yang lain-lainnya (Rustian, 2012).

Salah satu media sosial adalah Instagram yang berisikan foto, dan video dari akun yang memiliki tujuan tertentu. Hal ini yang menjadi pintubagi@indomusikgram untuk memanfaatkan media sosial instagram. Akun Komunitas Video Musik ini menjadikan akunnya sebagai wadah untuk berkomunikasi dan berbagi informasi mengenai musik. Kegiatan yang dilakukan adalah repost atau memuat ulang video-video rekaman menyanyi atau memainkan alat musik yang di unggah oleh individu di instagram dan ingin video-nya dimuat oleh @indomusikgram dengan cara mencantumkan hashtag \#indomusikgram dalam caption pada video rekaman yang di post di instagramnya. (@ indomusikgram).

Akun @Indomusikgram lahir pada Juli 2014 oleh Christian Bong. Pemilik dari akun ini adalah pencinta musik dan ingin masyarakat paham sejarah musik. Itulah mengapa dalam beberapa kesempatan, akun ini menyelipkan video-video yang bisa memancing diskusi tentang musik. Akun komunitas video musik ini telah berkibar hingga ke dunia internasional, banyak dari musisi vlogger di luar negeri yang mengirim pesan ke akun @ indomusikgram agar video nya dapat dimuat. Hal ini tentu membawa nama Indonesia ke mancanegara, khususnya pada bidang musik. (hitsss.com, 2017).

Pada penelitan ini peneliti ingin mengetahui bagaimana Instagram menjadi platform media komunikasi bagi komunitas videomusik@ Indomusikgram.

\section{TINJAUAN PUSTAKA}

\section{New Media (Media Baru)}

Hadirnya media sosial adalah bentuk dari media baru, yang telah dikembangkan sejak tahun 1980-an hingga saat ini. Hal ini menjadi sebuah perubahan pada konsep media, di mana konsep media tidak lagi mass melainkan dapat menjadi keperluan atau pencapaian dan jangkauan yang sangat pribadi. Konsep media baru mengemukakan konsep interaksi dari informasi pribadi (Littlejohn \& Foss, 2009: 143).

Media baru yang akan dibahas pada penelitian ini adalah media sebagai perangkat teknologi komunikasi yang perangkatnya memiliki ciri mirip dengan lainnya dan memiliki karakter digitalisasi bagi penggunanya berkomunikasi. (McQuail, 2010: 148).

Salah satu jenis dari media baru adalah media sosial dan salah satu yang paling terkenal pada saat ini adalah media sosial Instagram, yang menjadi platform yang digunakan @indomusikgram. Pengguna Instagram bertambah 1 juta dalam kurun waktu hanya 12 jam rata-rata 5 juta tiap minggu (@ mrbambang, 2012: 15).

Instagram adalah aplikasi berbasis ponsel yang mempersilahkan penggunanya untuk mengunggah foto/video sebagai bentuk penyampaian pesan untuk berkomunikasi. (@mrbambang, 2012: 17).

\section{Teori Cyber community}

Cyber community merupakan teori komunikasi komunitas virtual yang relevan pada penelitian ini karena juga membahas komunitas virtual. Cyber community membahas dunia cyber seperti perumpamaan "ruang waktu" yang mengemukakan bahwa ada kehidupan baru di dalam dunia virtual. (Bungin, 2009: 296). Community as place, arti dari elemen ini adalah membahas cyber space tempat di mana komunitas dibangun dan bertahan. Contoh: Letak geografis yang tidak memerlukan kesadaran kolektif atau terjadi dengan sendirinya untuk anggota menjadi akrab juga faktor persamaan kesukaan dan tujuan juga identitias, kemudian anggota menjadi sebuah komuni atau persekutuan (Holmes, 2012: 360).

Community as symbol, adalah simbol yang dimiliki oleh komunitas yang dapat diintepretasikan (Holmes, 2012: 429). Sebuah komunitas virtual yang baik dalam perspektif teori cyber community adalah komunitas yang memiliki karakteristik yang sama dari apa yang dikemukakan di atas. Komunitas musik@indomusikgram adalah komunitas virtual dan teori cyber community adalah teori yang pas bagi penelitian ini, karena dapat akan dapat melihat kualitas dan aktifitas komunikasi pada komunitas virtualmusik@indomusikgram.

\section{METODE}

Metode pada penelitian ini adalah kualitatif dari paradigma post-postivistik, yang ingin mencari 
tahu penjelasan dari suatu fenomena yang terjadi. Kualitatif adalah penelitian yang memiliki kepercayaan bahwa pengetahuan yang benar adalah pengetahuan yang didasarkan pada faktafakta yang berada di sekitar subjek penelitian. Fakta fakta tersebut diperoleh melalui proses pengindraan dari observasi (Pambayun, 2013:5).

Pengumpulan data pada penelitian ini menggunakan metode teknik dokumentasi, di mana data didapatkan pada dokumen yang diplubikasikan berbentuk gambar, tulisan dan catatan peristiwa (Sugiyono, 2013:145).

Data-data yang didapatkan dari studi dokumen dapat dilihat melalui proses teknik observasi di mana informasi dan data diamati oleh peneliti dalam proses pengmatan dan ingatan dari apa yang dilihat, didengar dan yang relevan pada penelitian (Sugiyono, 2013:145).

Pada penelitian ini, peneliti mengobservasi data-data yang ditemukan pada artikel yang dimuat tentang @indomusikgram, data-data yang dimuat oleh @indomusikgram dan proses komunikasi yang terjadi di @indomusikgram. Sumber utama yang didapatkan adalah dari akun @indomusikgram di instagram.

\section{HASIL DAN PEMBAHASAN}

@indomusikgram adalah salah satu akun yang diminati oleh para pecinta musik. Lahirnya komunitas video musik adalah gebrakan baru bagi tanah air Indonesia, di mana dulu sebelum lahirnya@indomusikgram, pecinta musik yang ingin mengakses online cenderung untuk memiliki idolanya sendiri atau mencari secara manual video siapa yang ingin ditonton. Kini musisi ada di satu wadah. Konten yang di repost setiap harinya oleh @ indomusikgram adalah cover version dari lagu yang sudah ter-publish resmi. (Sebagai contoh: Cover Lagu Mantan Terindah - Raisa).

Selain@indomusikgram adalah sebuah akun yang bertujuan dengan menciptakan komunitas musik, @indomusikgram juga membuka peluangpeluang lain yang dapat menjadi tempat untuk meningkatkan karir dari musisi itu sendiri. @ indomusikgram juga membuka peluang kerjasama secara profesional (paid post) bagi siapapun yang ingin promosi single atau album yang baru dengan syarat dan ketentuan yang akan dibicarakan lebih lanjut. Yang pertama mendengar musiknya, apakah layak (suara atau lead instrument tidak pitchy parah, dan secara musik iringan juga rapih atau terdengar jelas). @Indomusikgram selalu mengutamakan creator orang Indonesia, namun hal ini tidak menutup kemungkinan untuk @ indomusikgram me-repost creator internasional (Indomusikgram, 2016).

Akun@Indomusikgram lahir pada Juli 2014 oleh Christian Bong. Akun ini sendiri bertugas menyeleksi siapa saja talenta berbakat di Instagram melalui tagar/hashtag \#indomusikgram. Saat ini, isi Instagram dari Indomusikgram tidak selalu berisi regram/ repost dari akun lain, namun pemilik dari akun ini juga ingin masyarakat paham sejarah musik. Itulah mengapa dalam beberapa kesempatan, akun ini menyelipkan video-video yang bisa memancing diskusi tentang musik. Akun komunitas video musik ini telah berkibar hingga ke dunia internasional, banyak dari musisi vlogger di luar negeri yang mengirim pesan ke akun @ indomusikgram agar video nya dapat dimuat. Hal ini tentu membawa nama Indonesia ke manca negara, khususnya pada bidang musik (hitsss.com, 2017).

@indomusikgram memiliki 688 ribu followers dengan 4,645 posting dari dalam negeri dan luar negeri. Namun, tentu mayoritas dan prioritas utama adalah masyarakat Indonesia. Posting dari @ indomusikgram adalah video-video cover musik dari individu/kelompok, dengan perkembangan zaman, hanya dengan repost video dari akun orang lain, ternyata dapat membentuk sebuah komunitas.

\section{Pendekatan Cyber community}

Community as a place, sebagai tempat komunitas dibangun dan bertahan. Jenis komunitas diantaranya berdasarkan keakraban secara geografis yang tidak memerlukan proses kesadaran yang berarti keakraban terjadi dengan sendiirnya, ada juga rasa persamaan yang menjadikan sekutu (Holmes, 2012: 360). @Indomusikgram adalah komunitas yang berdiri mengatasnamakan Indonesia, oleh rakyat Indonesia dan untuk Indonesia. Dengan demikian secara geografis @ indomusikgram telah menjajaki Indonesia sebagai pendekatan geografis.

Keakraban dari pengikut @indomusikgram yang mayoritas adalah rakyat Indonesia dapat terjadi secara otomatis karena pengikut berasal dari tanah air yang sama, berbahasa yang sama dan cenderung memilki cara komunikasi yang sama. Meskipun komunitas ini adalah komunitas di dunia maya, keakraban dari pengikut yang dapat dilihat dari kolom komen tetap terjaga. Setiap kali ada 
video baru yang di post, selalu dibanjiri komentar. Komentar juga terkadang menjadi wadah diskusi.

@indomusikgram juga cenderung membuat caption yang mengajak diskusi agar pengikut dapat menyatakan pendapat dan dapat berdiskusi dalam kolom komentar. Meski hanya dapat berkomunikasi satu sama lain melalui kolom komentar, antusias dari pengikut akun @indomusikgram tetap tinggi.

Selain pada caption, @Indomusikgram juga terkadang memuat foto yang beriskan pertanyaan untuk mengajak pengikut berkomentar dan beropini. Contoh dari pertanyaan yang muat oleh @indomusikgram adalah "Ayo Ceritakan Lagu Yang Paling Berkesan Buat Kamu!" yang di post pada tanggal 12 November 2017. Pertanyaan tersebut dibanjiri oleh komentar yang bersifat beragam, ada yang hanya menjawab pertanyaan, ada yang menyampaikan alasan mengapa, ada yang bercerita singkat tentang hidupnya dan sebagainya.

Akun@Chuaaqila menjawab pada kolom komentar dengan jawaban "Lagu Satu aku sayang ibu" karena itu lagu pertama yang aku tau pas kecil, dulu pernah diceritain sama ortu". Hal ini menunjukan bahwa pengikut dari akun @i ndomusikgram merasa nyaman untuk beropini, menyampaikan pendapat hingga bercerita pada kolom komunitas ini. Sesuai dari apa yang dikatakan oleh penemu dan juga pemilik @Indomusikgram, akun ini juga menampakan khas dari Indonesia seperti video yang diunggah pada tanggal 10 November 2017.

Terlihat seseorang memainkan alat musik tradisional Indonesia. Kemudian terjadi sebuah diskusi dan pertanyaan mengenai nama alat musik tradisional tersebut seperti yang ditanyakan oleh akun @jorvenys "Itu nama alat musiknya apa ya plis yang tau dong saya buta alat musi daerah hehe" yang kemudian dijawab oleh @ edwardusboy "namanya sape dari kalimantan". Kegiatan komunikasi antar pengikut dari akun @ indomusikgram terlihat hidup dan berbobot. Bukan hanya sharing belaka namun melalui komunitas ini, masyarakat dapat belajar tentang musik Indonesia.

Hal ini yang juga menjadi aspek pendekatan geografis, di mana pengikutnya mayoritas Indonesia maka hal-hal yang didiskusikan dapat diserap oleh pengikut yang ingin ikut berdiskusi.

Selain itu, dengan pengikut akun ini dan juga yang aktif membalas dalam kolom komentar, juga yang sering menyukai posting dariakun @ indomusikgram kemudian menjadikan seluruh individu yang menjadi bagian dari aktifitas komunikas di komunitas ini adalah tempat untuk sebuah perseketuan, yaitu persekutuan masyarakat menyukai musik.

\section{Community as a Symbol}

Seperti komunitas pada umunya, komunitas cyber juga memiliki simbol-simbol yang dapat diartikan atau diinterpretasikan (Holmes, 2012: 429). Dari posting yang dilakukan oleh @indomusikgram sudah menjadi simbol bagi komunitasnya. Selain akun ini telah menuliskannya pada kolom biodata bahwa akun ini adalah akun "Komunitas Video Musik" namun isi dari posting instagramnya sudah menjadi simbol tersendiri. Posting yang berisikan seseorang bernyanyi, memainkan musik atau apa saja yang memiliki hubungan dengan musik. Maka simbol yang ingin disampaikan kepada khalayak adalah 'Musik'.

Selain itu, nama dari akun ini adalah indomusik-gram di mana kata Indo didapatkan dari kata Indonesia, kemudian gram dari kata Instagram. Maka dapat disimpulkan bahwa simbol yang ingin diberikan kepada masyarakat adalah bahwa akun ini adalah akun musik di Instagram yang datang dari Indonesia juga berisikan musik-musik yang merepresentasikan Indonesia.

\section{Community as Virtual}

Norma-norma, aturan-aturan dan identitas bersama yang ditujukan dari komitmen atau kepentingan di antara komunitas lainya (Holmes, 2012: 428). Seperti Komunitas lainnya, tentu @ indomusikgram memiliki norma-norma, aturanaturan dan identitas bersama, hal ini dicantumkan @indomusikgram pada biodata pada akunnya dalam bentuk link. Link bit.ly/imgrules ini ditujukan siapapun yang ingin bekerjasama dengan komunitas ini. Hal ini yang menjadi panduan, norma dan regulasi yang ditetapkan oleh @indomusikgram demi kesejahteraan komunitas dan tentunya nama baik dari komunitas ini sendiri.

Link tersebut membawa siapapun yang mengaksesnya ke halaman facebook (indomusikgram, 2016 Juli 30). @indomusikgram yang berisikan aturan-aturan yang ditetapkan. Poinpoin di antaranya adalah:

1. Akun @indomusikgram tidak menerima kiriman/titipan posting melalui jalur apapun kecuali hashtag \#indomusikgram di Instagram atau pilihan kurator kami melalui sumber lain seperti Facebook atau YouTube. 
2. Konten yang di setiap harinya dari \#indomusikgram adalah cover version dari lagu yang sudah ter-publish resmi.

3. Membuka peluang kerjasama secara profesional (paid post) bagi siapapun yang ingin promosi single atau album.

4. Menilai sebuah video itu dari kejelasan gambar, audio dan kreatifitas.

5. Tidak tanggung jawab atas plagiat, jika ditemukan plagiat akan di blacklist.

6. Kami mendukung segala bentuk acara atau komunitas dan event lokal.

7. Kami akan selalu mengutamakan kreator orang Indonesia, namun tetap terbuka dengan creator Internasional.

8. Tidak ada ekslusivitas terhadap siapapun.

@indomuskgram serius dalam membuat komunitas ini, dilihat dari pembungkusan dan strategi produksi yang ia kemukakan dengan cukup jelas bagi para creator jika ingin bergabung. Akun ini sangat memanfaatkan fitur-fitur yang ada di Instagram, di mana semua produksinya di lakukan di media sosial Instagram. Ini membuktikan bahwa komunitas dapat berjalan di mana saja dengan anggota yang tinggal di mana saja.

Hadirnya media baru dalam bentuk media sosial Instagram ini, membuat khalayak menjadi kreatif. Dari yang sebelumnya hanyalah penonton acara televisi atau pendengar radio, kini mereka dapat berinovasi dan menjadi produser untuk karyanya sendiri. Fenomena ini sangat unik karena, seseorang yang sebelumnya tidak memiliki keahlian dalam bidang teknologi kini beralih kepada teknologi untuk mengembangkan karir atau inovasinya seperti @ indomusikgram yang dimulai dengan fenomena seseorang menyukai musik, kemudian menciptakan sebuah komunitas yang juga menjadi wadah bagi musisi di Indonesia untuk melebarkan sayapnya.

Dahulu, musisi bersusah payah untuk mencari studio rekaman atau rumah produksi yang ingin membeli atau memproduksi musiknya, kini mereka dengan mudah dapat hanya bermain gitar dirumah merekamnya, diunggah ke sosial media dengan tagar \#indomusikgram, dan akan mendapatkan kesempatan untuk di-share kepada ribuan followers bahkan jutaan publik lainnya di seluruh dunia. Hal ini tentu adalah, inovasi dan fenomena yang patut untuk dipelajari dan diapresiasi. Musisi Indonesia kini dapat meraih khalayak dengan mudah

\section{SIMPULAN}

Pada kesimpulannya@Indomusikgram @ indomusikgram memanfaatkan media sosial Instagram sebagai alat untuk mengembangkan tujuannya dalam menciptakan komunitas musik dari Indonesia. Adapun sifat-sifat proses komunikasi dalam pemanfaatan media sosial Instagram adalah penerapan dari sifat cyber community. @ Indomusikgram memiliki sifat cyber community di mana akun tersebut adalah sebuat tempat bagi pengikutnya dan menggunakan Indonesia sebagai pendekatan geografis yang kemudian mempererat komunitas tersebut menjadi sebuah sekutu. Selain itu, @indomusikgram menggunakan simbol Indonesia, musik dan Instagram sebagai simbol dari akunnya di mana simbol ini menggambarkan komunitas musik yang berletak di Indonesia menggunakan instagram sebagai media komunikasi yang memiliki norma dan aturan untuk mempertahakan identitas dan keeksistensian dari komunitas. Norma dan aturan yang diterapkan juga dikomunikasikan secara jelas dan diakses dengan mudah bagi para musisi yang ingin ikut menjadi bagian dari komunitas ini, untuk videonya diunggah oleh@indomusikgram.

\section{DAFTAR PUSTAKA}

@Indomusikgram.(n.d) diakses dari https://www. instagram.co $\mathrm{m} /$ indomusikgram/?hl=en

@mrbambang. (2012). Instagram Handbook. Jakarta: PT. Trans Media.

Bungin. B. (2009). Analisis Penelitian Kualitatif. Jakarta: PT. Raja Grafindo Persada.

hitsss.com. (2017). Menduniakan Musik Indonesia Melalui hitts. \#INDOMUSIKGRAM. Diakses dari https://www.hitsss. $\mathrm{com} / \mathrm{m}$ enduniakan-musik-indonesiamelalui-indomusikgram/

Holmes, D. (2012). Teori Komunikasi: Media, Teknologi, dan Masyarakat. Yogyakarta: Pustaka Pelajar.

Indomusikgram. (2016,). Indomusikgram Rule. Diakses dari https://web. facebook.com /notes/indomusikgram/ indomusikgram-rules/636018743225245? rdc $=1 \&$ \& $r$ r

Little John, S. \& Foss. (2009). Teori Komunikasi. Jakarta: Salemba Humanika. 
Mc Quail. D. (2010). Teori Komunikasi Massa. Jakarta: Salemba Humanika.

Pambayun, E. L. (2013). Qualitative Research Methodology in Communication. Jakarta: Penerbit Lentera IImu Cendekia.

Rustian, S. F., (2012). Apa itu Media Sosial. Diakses dari http://www.unpas.ac.id/apa-itu-sosialmedia/.

Sugiyono. (2013). Metode Penelitian Kuantitatif, Kualitatif dan R\&D. Bandung: Alfabeta. 